\title{
Effect of potato fiber on survival of Lactobacillus species at simulated gastric conditions and composition of the gut microbiota in vitro
}

Citation for published version (APA):

Larsen, N., de Souza, C. B., Krych, L., Kot, W., Leser, T. D., Sorensen, O. B., Blennow, A., Venema, K., \& Jespersen, L. (2019). Effect of potato fiber on survival of Lactobacillus species at simulated gastric conditions and composition of the gut microbiota in vitro. Food Research International, 125, [108644]. https://doi.org/10.1016/j.foodres.2019.108644

Document status and date:

Published: 01/11/2019

DOI:

10.1016/j.foodres.2019.108644

Document Version:

Publisher's PDF, also known as Version of record

\section{Document license:}

Taverne

Please check the document version of this publication:

- A submitted manuscript is the version of the article upon submission and before peer-review. There can be important differences between the submitted version and the official published version of record.

People interested in the research are advised to contact the author for the final version of the publication, or visit the DOI to the publisher's website.

- The final author version and the galley proof are versions of the publication after peer review.

- The final published version features the final layout of the paper including the volume, issue and page numbers.

Link to publication

\footnotetext{
General rights rights.

- You may freely distribute the URL identifying the publication in the public portal. please follow below link for the End User Agreement:

www.umlib.nl/taverne-license

Take down policy

If you believe that this document breaches copyright please contact us at:

repository@maastrichtuniversity.nl

providing details and we will investigate your claim.
}

Copyright and moral rights for the publications made accessible in the public portal are retained by the authors and/or other copyright owners and it is a condition of accessing publications that users recognise and abide by the legal requirements associated with these

- Users may download and print one copy of any publication from the public portal for the purpose of private study or research.

- You may not further distribute the material or use it for any profit-making activity or commercial gain

If the publication is distributed under the terms of Article $25 \mathrm{fa}$ of the Dutch Copyright Act, indicated by the "Taverne" license above, 


\title{
Effect of potato fiber on survival of Lactobacillus species at simulated gastric conditions and composition of the gut microbiota in vitro
}

\author{
Nadja Larsen ${ }^{\mathrm{a}, *}$, Carlota Bussolo de Souza ${ }^{\mathrm{b}}$, Lukasz Krych ${ }^{\mathrm{a}}$, Witold Kot ${ }^{\mathrm{c}}$, Thomas Dyrmann Leser ${ }^{\mathrm{d}}$, \\ Ole Bandsholm Sørensen ${ }^{\mathrm{e}}$, Andreas Blennow ${ }^{\mathrm{f}}$, Koen Venema ${ }^{\mathrm{b}}$, Lene Jespersen ${ }^{\mathrm{a}}$ \\ ${ }^{a}$ Department of Food Science, University of Copenhagen, Frederiksberg C 1958, Denmark \\ ${ }^{\mathrm{b}}$ Center for Healthy Eating and Food Innovation, Maastricht University - campus Venlo, the Netherlands \\ ${ }^{c}$ Department of Environmental Science, Aarhus University, Roskilde, Denmark \\ ${ }^{\mathrm{d}}$ Chr. Hansen A/S, Hoersholm, Denmark \\ ${ }^{\mathrm{e}} \mathrm{KMC}$, Brande, Denmark \\ ${ }^{\mathrm{f}}$ Department of Plant and Environmental Sciences, University of Copenhagen, Frederiksberg C 1958, Denmark
}

\section{A R T I C L E I N F O}

\section{Keywords:}

Potato fiber

Starch

Lactobacillus spp.

Gut microbiota

TIM-2 colon model

\begin{abstract}
A B S T R A C T
Potato fiber is a side product in starch manufacturing rich in dietary fibers such as pectin, cellulose, hemicellulose and resistant starch. So far, the beneficial properties of potato fiber have been poorly characterized. This study investigated the effect of FiberBind 400, a commercial potato fiber product, on survival of probiotic Lactobacillus strains at simulated gastric conditions and on the composition and metabolic activity of the gut microbiota, using the TIM-2 colon model. Resistant starch and native starch from potato were used as reference substrates. FiberBind 400 had an ability to improve survival of the four tested strains, Lactobacillus fermentum PCC ${ }^{\circledast}$, L. rhamnosus $\mathrm{LGG}^{\circledast}$, L. reuteri RC- $14^{\circledast}$ and L. paracasei F-19 ${ }^{\circledast}$ in a strain-dependent way. The highest effect was observed for L. fermentum PCC ${ }^{\circledR}$ and L. rhamnosus LGG $^{\circledR}$. The effect of starches on bacterial survival was insignificant. Composition of the fecal microbiota in TIM-2 fermentations was assessed by high-throughput sequencing of $16 \mathrm{~S}$ rRNA gene amplicon. Fermentation of FiberBind 400 resulted in more diverse microbial communities compared to starches. Changes in microbial abundances specifically mediated by FiberBind 400, included increases in the genera Lachnospira, Butyrivibrio, Mogibacterium, Parabacteroides, Prevotella and Desulfovibrio, and the species B. ovatus, as well as decreases in Ruminococcus torques and unassigned Ruminococcus spp. Shifts in other bacterial populations, such as increased abundances of Oscillospira, Enterococcus, Bacteroidales, Citrobacter, along with reduction of Roseburia, Ruminococcus, and Faecalibacterium prausnitzii were not significantly different between the substrates. Cumulative production of individual short-chain fatty acids was similar between potato fiber and starches. The study demonstrated that FiberBind 400 had a potential to protect probiotic Lactobacillus strains during the passage through the gastrointestinal tract and selectively modulate the gut bacterial populations. This knowledge can support application of potato fiber as a functional food ingredient with added biological benefits.
\end{abstract}

\section{Introduction}

Dietary fibers (DF) are typically plant polysaccharides indigestible by enzymes in the human intestine. Reaching the colon, DF can be degraded and utilized by the gut bacteria with production of shortchain fatty acids (SCFA), gases and other metabolites (Lockyer \& Nugent, 2017). The types of dietary fibers, which can be selectively utilized by host microorganisms, conferring a health benefit are claimed as prebiotics (Gibson et al., 2017). The effects of DF on the gut health are mediated through the compositional changes of the gut microbiota and production of microbial metabolites, and depend to a large extent on the fiber type (Wang et al., 2019). One of the potential candidates of prebiotic fibers is potato fiber, a side product of starch manufacturing rich in starch, pectin, cellulose and hemicellulose (Lovegrove et al., 2017; Pastuszewska, Antushevich, Tuśnio, \& Taciak, 2009; Zhao, Andersson, \& Andersson, 2018). The yield of potato fiber is about $14 \mathrm{~kg}$ per ton of starch potatoes, and only in Europe potato fiber is currently produced in millions of tons per year (Grommers \& van der Krogt, 2009; Starch EU, 2018). In addition to a rapidly digestible starch, potato fiber contains resistant starch (RS), which nutritional properties, digestibility

\footnotetext{
* Corresponding author at: Department of Food Science, University of Copenhagen, Rolighedsvej 26, 1958 Frederiksberg, Denmark.

E-mail address: nf@food.ku.dk (N. Larsen).
} 
and beneficial effects in the gut have been extensively characterized (Yang et al., 2017; Zhang et al., 2015). Human intervention studies demonstrated that dietary supplementation with resistant starch improved glycemic status and inflammatory markers in patients with type 2 diabetes and metabolic syndrome (Johnston, Thomas, Bell, Frost, \& Robertson, 2010; Karimi et al., 2016). It has been suggested that replacing digestible dietary starches with resistant starch would contribute to weight management due to the lower calorie content and energy density (Zhang et al., 2015). The prebiotic potential of pectins, another component of potato fiber, was also confirmed by several in vitro and in vivo studies, showing the ability of pectins to modulate specific populations of fecal microbiota, to induce gut immunity, decrease energy intake and improve intestinal integrity (Fukunaga et al., 2003; Gómez, Gullón, Yáñez, Schols, \& Alonso, 2016; Larsen et al., 2019; Salleh, Fairus, Zahary, Bhaskar Raj, \& Mhd Jalil, 2019). Furthermore, both resistant starch and pectins can be beneficially used for microencapsulation of Lactobacillus spp. and Bifidobacterium spp., to increase viability of bacterial cells during the gastro-intestinal transit (Etchepare et al., 2016; Zanjani, Ehsani, Tarzi, \& Sharifan, 2018). Recently, we demonstrated that the ability of pectins to protect probiotic Lactobacillus strains exposed to intestinal stresses was influenced by the structural and physical properties, among them, degrees of methylation and branching, surface charges, molecular weight and viscosity (Larsen, Cahú, Saad, Blennow, \& Jespersen, 2018). Though extensive data exists on the individual components, the role of potato fiber as a whole is investigated insufficiently. A few published studies indicated that dietary potato fiber given to rodents stimulated caecal fermentation, improved mineral absorption (Pastuszewska, Taciak, Tuśnio, \& Misztal, 2010) and attenuated inflammation during induced colitis in rats, potentially through SCFA production (Panasevich et al., 2015). A combination of potato fiber and red meat diets in rats balanced the harmful impact of red meat by increasing colonic Bifidobacterium spp. and improving biomarkers of bowel health (Paturi et al., 2012).

The growing evidence of beneficial impact of dietary fibers encourages a search for the new fiber-based products. This study focused on commercial potato fiber produced under the brand name FiberBind 400 (KMC, Denmark). The product has a high water-binding capacity and can be applied as a functional ingredient (stabilizer) in such food products as sausages and cold cuts. This in vitro study investigated the prebiotic potential of FiberBind 400, including its ability to increase survival of probiotic Lactobacillus strains at gastro-intestinal conditions and to modulate the gut microbiota. The reference substrates, native starch and resistant starches from potato, were included in the experiments for data comparison. The microbiota fermentations were performed in TIM-2 model of proximal colon, developed by The Netherlands Organization for Applied Scientific Research (TNO).

\section{Methods}

\subsection{Potato fiber and starches}

FiberBind 400 and starches were commercial products from a potato variety Solanum tuberosum produced at KMC (Brande, Denmark). According to the KMC certificate (unpublished data), FiberBind 400 contained per $100 \mathrm{~g}$ : $65 \mathrm{~g}$ dietary fiber (pectin, cellulose and hemicellulose), $20 \mathrm{~g}$ starch, $5 \mathrm{~g}$ protein, $2 \mathrm{~g}$ fat and $0.5 \mathrm{~g}$ sodium chloride. The starch fraction was composed of digestible starch and resistant starch fractions, accounting for $12 \%$ and $8 \%$ of FiberBind 400 , respectively. Reference substrates in this study were native potato starch (NS) and cross-linked resistant starch from potato (RS). Reagents for the experiments were purchased from Merck A/S (Hellerup, Denmark) and Sigma-Aldrich Aps (Broendby, Denmark) unless otherwise stated.

\subsection{High Performance Anion Exchange Chromatography}

Composition of monosaccharides in FiberBind 400 was determined by High Performance Anion Exchange Chromatography with Pulsed Amperometric Detection (HPAEC-PAD) as reported previously (Larsen et al., 2018). Shortly, suspensions of FiberBind 400 in water were hydrolysed in trifluoroacetic acid and injected into PA20 column (Dionex, CA, USA). Before injection the column was washed and equilibrated with $\mathrm{NaOH}$. The elution program included an isocratic elution with water, followed by a linear gradient elution with $\mathrm{NaOH}$ (up to $1 \mathrm{M}$ ). Calibration was performed with a standard solution containing galacturonic acid, arabinose, rhamnose, galactose, glucose and xylose. The HPAEC-PAD analyses were performed in duplicates.

\subsection{Bacterial strains and growth conditions}

Commercial probiotics Lactobacillus fermentum PCC ${ }^{\circledR}$, Lactobacillus reuteri RC-14 ${ }^{\circledR}$, Lactobacillus paracasei subsp. paracasei $\mathrm{F}-19^{\circledR}$ and Lactobacillus rhamnosus LGG $^{\oplus}$ were provided by Chr. Hansen A/S (Hoersholm, Denmark). Strains were maintained in de Man Rogosa Sharpe (MRS) broth (Becton Dickinson A/S, Albertslund, Denmark) with $20 \%(v / v)$ glycerol at $-80^{\circ} \mathrm{C}$. Before the experiments bacterial strains were plated onto MRS agar and incubated anaerobically (AnaeroGen sachets; Oxoid A/S, Roskilde, Denmark) at $37^{\circ} \mathrm{C}$ for $48 \mathrm{~h}$.

\subsection{Test of bacterial survival at simulated gastric conditions}

Bacterial survival was tested in the simulated gastric solution (GS) which contained $0.31 \mathrm{~g}$ sodium chloride, $0.11 \mathrm{~g}$ potassium chloride, $0.06 \mathrm{~g}$ sodium bicarbonate, $0.06 \mathrm{~g}$ calcium chloride dehydrate, $8 \mathrm{U} / \mathrm{ml}$ lipase (from porcine pancreas) and $120 \mathrm{U} / \mathrm{ml}$ pepsin (from porcine gastric mucosa) in a total volume of $100 \mathrm{ml}$ citrate/phosphate buffer (final concentration 0.1 M) (Barker, Abrahamsson, \& Kruusmägi, 2014). The $\mathrm{pH}$ was adjusted to $2.5( \pm 0.01)$ with $0.1 \mathrm{M} \mathrm{HCl}$. Potato fiber, native starch or resistant starch were added to GS $(1 \%(w / v))$ for test experiments and MilliQ water was added for controls. Bacterial strains were inoculated in MRS broth from a single colony on the MRS agar plates and grown overnight anaerobically at $37^{\circ} \mathrm{C}$. Cells from overnight cultures were re-suspended in saline solution $(0.85 \%(\mathrm{w} / \mathrm{v}) \mathrm{NaCl})$ and added to the GS test and control solutions to a final cell density of $10^{9} \mathrm{CFU} / \mathrm{ml}$. Survival kinetics of the strains was followed during incubation at $37^{\circ} \mathrm{C}$ by flow cytometry and standard plating on MRS agar. Experiments were performed in triplicates.

\subsection{Bacterial viability by flow cytometric analysis and plate counting}

To determine the changes in live cells fractions during incubation in GS, bacterial cells were collected by centrifugation, washed in saline solution and stained with fluorescent markers SYTO $^{\circledR} 13$ (Life Technologies Europe BV, Denmark) and propidium iodide (PI). Negative controls (dead cells), were prepared by treatment of cell suspensions with $70 \%$ ethanol before staining. Emission was recorded at $530 \pm 20 \mathrm{~nm}$ from SYTO $^{\circledR} 13$ stained cells (green fluorescence), and at $692 \pm 20 \mathrm{~nm}$ from PI stained cells (red fluorescence) using BD FACS Jazz Cell Sorter (BD Biosciences, USA). Subpopulations of live and dead cells were estimated from the dot plot images (cytograms) based on 100,000 events per sample using the FlowJo software (version 10, Tree Star Inc. USA). The colony forming units ( $\mathrm{CFU}$ ) were determined by plating serial dilutions of cell suspensions onto MRS agar after $4 \mathrm{~h}$ treatment of strains $L$. fermentum $\mathrm{PCC}^{\circledast}$ and $L$. reuteri $\mathrm{RC}-14^{\circledR}$, and after $1 \mathrm{~h}$ treatment of strains L. rhamnosus $\mathrm{LGG}^{\circledast}$ and L. paracasei $\mathrm{F}-19^{\circledR}$ to obtain at least $1 \log _{10} \mathrm{CFU}$ reduction. The MRS agar plates were incubated anaerobically at $37^{\circ} \mathrm{C}$ for $48 \mathrm{~h}$. Differences in $\log _{10} \mathrm{CFU}$ reduction between the treatments and control experiments were evaluated by the paired two-tailed Student's $t$-test (Microsoft Office Excel 2010). 


\subsection{TIM-2 fermentations and sample collection}

The TIM-2 colon model, including operational units, conditions of fermentation and sample loading has been described previously (Venema, 2015). Inoculum consisted of pooled fecal microbiota collected from 8 healthy Caucasian adults (male: $n=4$, female: $n=4$; age of 25-42 years). TIM-2 fermentations were performed with $30 \mathrm{ml}$ portion of microbiota at $37^{\circ} \mathrm{C}$ and $\mathrm{pH}$ 5.8. Before treatments the microbiota was incubated for $16 \mathrm{~h}$ for adaptation to the new environment. During the adaptation period the basal simulated ileal efflux medium (SIEM) was gradually introduced in a total volume of $40 \mathrm{ml}$ per unit; afterwards, the microbiota was deprived from any medium for $2 \mathrm{~h}$ (starvation period). The units were then fed with SIEM containing $7.5 \mathrm{~g}$ of FiberBind 400, native starch or resistant starch per day as the only carbohydrate source. Luminal and dialysate samples were collected at fermentation start $(0 \mathrm{~h})$ and after 24, 48, 56 and $72 \mathrm{~h}$ for analyses of microbiota composition, short-chain fatty acids (SCFA) and branchedchain fatty acids (BCFA). Fermentations of each substrate were performed as two independent TIM-2 experiments.

\subsection{DNA purification and sequencing}

The total bacterial DNA was purified using the PowerLyzer@ PowerSoil DNA Isolation Kit according to the manufacturer's protocol (Qiagen Nordic, Denmark). Before the bead beating step, fecal slurries were resuspended in the Bead Solution and incubated at $65^{\circ} \mathrm{C}$ for $10 \mathrm{~min}$. The homogenization was performed in three cycles, $30 \mathrm{~s}$ each with $30 \mathrm{~s}$ interval, at $6.5 \mathrm{~m} / \mathrm{s}$ (FastPrep ${ }^{\circledR}-24$, MP Biomedicals, Solon OH, USA). The DNA concentration was commonly between 20 and $100 \mathrm{ng} /$ $\mu 1$ and A260/A280 ratios were of 1.8-2.1 (NanoDrop $^{\mathrm{TM}} 2000$ Spectrophotometer, Thermofisher Scientific, Denmark). The DNA library was prepared as described previously (Larsen et al., 2019). In brief, the V3 region ( $\sim 190 \mathrm{bp})$ of the 16S rRNA gene was PCR amplified using AccuPrime SuperMix II (Life Technologies, CA, United States) and primers comparable with Nextera Index Kit, NXt_388F and NXt_518R (Illumina). To incorporate adapters and tags, the second PCR step was carried out using Phusion High-Fidelity PCR Master Mix (ThermoFisher Scientific, MA, United States) and primers P5 and P7 (Nextera Index Kit). Sequencing was conducted using $2 \times 150$ cycles, MID output and V2 chemistry on the Illumina NextSeq 500 platform (Illumina, CA, USA). The raw dataset containing pair-ended reads were merged, trimmed and clustered (operational taxonomic units, OTUs, with $97 \%$ similarity) using the UPARSE pipeline.

\subsection{Analysis of sequencing data and statistic}

Sequencing data were analyzed using QIIME software (version 1.8.0) (Caporaso et al., 2010) and the Greengenes database (version 13.8) for taxonomy annotation (Mcdonald et al., 2012). Alpha-diversity was evaluated by the number of observed species and Chao1 ( $97 \%$ similarity OTUs) computed for each OTU table rarefied to 10,000 sequences per sample, based on the lowest number of sequences produced per sample. Differences in alpha-diversity between the substrates were tested using Student's $t$-test, employing the non-parametric (Monte Carlo) method (999 permutations). Community differences (beta-diversity) were revealed using weighted and unweighted UniFrac distances matrices and evaluated by analysis of similarities (ANOSIM). A weighted UniFrac matrix is based on the absolute proportions, and it is most sensitive to distinguish abundant bacterial populations, while an unweighted matrix relies on the presence or absence of bacteria, accounting for both dominant and rare taxa. Data matrix was built with sample number ( $n=30$, columns) versus species number (1059 OTU, rows). Principal Coordinate Analysis (PCoA) plots were generated with Jackknifed Beta Diversity workflow using 10 subsampled OTU tables. Bacterial abundances in the pooled data set (48, 56 and $72 \mathrm{~h}$ ) obtained in two independent experiments ( $n=6$ for each substrate) were compared to fermentation start ( 0 h, $n=6)$. Statistical differences were assessed by the nonparametric Wilcoxon Rank Sum test combined with Bonferroni multiplicity correction, using 0.05 as significance level.

\subsection{Analysis of short-chain and branched-chain fatty acids}

Cumulative production of SCFA and BCFA was quantified in the lumen and dialysate TIM-2 samples by Brightlabs (Venlo, the Netherlands). Supernatants were diluted with $1.5 \mathrm{mM}$ sulfuric acid and injected onto an 883 Basic IC plus ion-chromatography system (Metrohm, Herisa, Switzerland). The acids were eluted at a flow rate of $0.4 \mathrm{ml} / \mathrm{min}$ with a pressure of $5.5 \mathrm{MPa}$ at $65^{\circ} \mathrm{C}$ using ICsep ION300 Ion exclusion column and Metrosep RP2 Guard column (Transgenomic, New Haven, CT, USA). Acetic, propionic, butyric, isobutyric and isovaleric acids were used as calibration standards (Sigma Chemical, St. Louis, MO). Differences in production of SCFA and BCFA were evaluated by the paired two-tailed Student's $t$-test (significance level $p<.05)$.

\section{Results}

\subsection{Composition of potato fiber FiberBind 400}

The major components of potato fiber included dietary fiber, i.e., pectin, cellulose and hemicellulose, and starch (KMC certificate, unpublished data). Neutral sugar analysis of FiberBind 400 showed that $48.0 \%$ of total monosaccharides was glucose, originating primarily from the starch, cellulose and pectin components. The other dominant sugar residues were galactose $14.8 \%$, arabinose $11.8 \%$ and xylose $9.6 \%$, the common constituents of pectin and hemicellulose molecules (Chan, Choo, Young, \& Loh, 2017). In addition, pectin in FiberBind 400 was a source of galacturonic acid (13.1\%) and rhamnose in low amounts (0.5\%).

\subsection{Survival of Lactobacillus spp. in gastric solution as affected by potato fiber}

Viability of the tested Lactobacillus strains in gastric solution was strain-specific and significantly improved in the presence of FiberBind 400 compared to control experiments (GS without added carbohydrates) as determined by flow cytometry (Fig. 1). The highest increase in live cell fractions was observed for L. fermentum PCC ${ }^{\circledR}$ and L. rhamnosus LGG $^{\circledast}$ throughout the whole incubation period (Fig. $1 \mathrm{~A}$ and C). Thus, the live cells of $L$. fermentum PCC ${ }^{\circledast}$ comprised $45.9 \pm 5.5 \%$ after $6 \mathrm{~h}$ treatment with potato fiber compared to $4.8 \pm 2.2 \%$ in controls; while the live cells of L.rhamnosus LGG $^{\otimes}$ were increased to $18.8 \pm 6.1 \%$ at the end of test incubations $(2 \mathrm{~h}$ ) versus $0.8 \pm 1.6 \%$ in controls. The live cells percentage of $L$. reuteri $\mathrm{RC}-14^{\circledR}$ and $L$. paracasei $\mathrm{F}$ $19^{\circledR}$ was increased by potato fiber mainly in the first part of incubation (Fig. 1B and D). The flow cytometry results were confirmed by CFU plating, showing an increase of viable counts of Lactobacillus spp. in gastric solution in the presence of FiberBind 400 compared to control incubations (Fig. S1, Supplementary Material). The effect of starches on bacterial resistance to gastric solution was not statistically different from controls (Figs. 1 and S1).

\subsection{Alpha-diversity of microbiota}

Alpha-diversity of microbiota over time is presented by Chao1 indices (Fig. 2) and rarefaction curves computed for the observed species number (Fig. S2, Supplementary Material). Fermentations of FiberBind 400 resulted in significant increase of alpha-diversity levels between 24 and $56 \mathrm{~h}$ (Chao1 of 747-758). In starch fermentations the increase in diversity was recorded after $24 \mathrm{~h}$ (Chao1 of $738 \pm 29$ for resistant starch and $773 \pm 40$ for native starch), followed by gradual decrease, lowest in native starch fermentations (Chao1 of $631 \pm 37$ after $72 \mathrm{~h}$ ). 
A

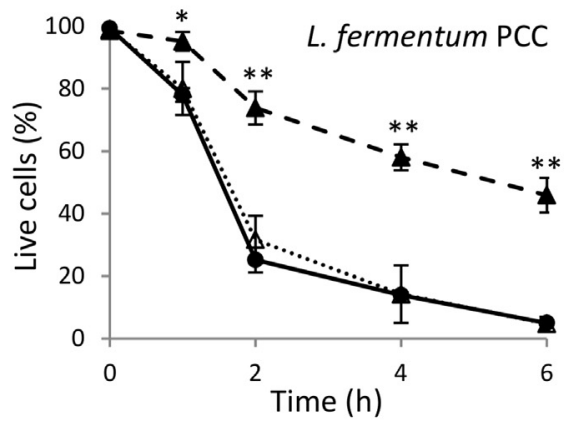

C

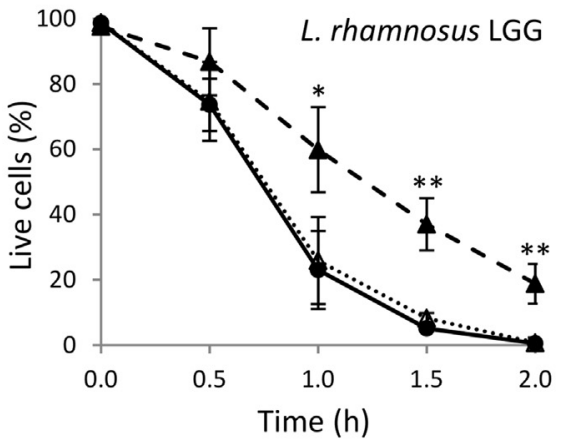

B

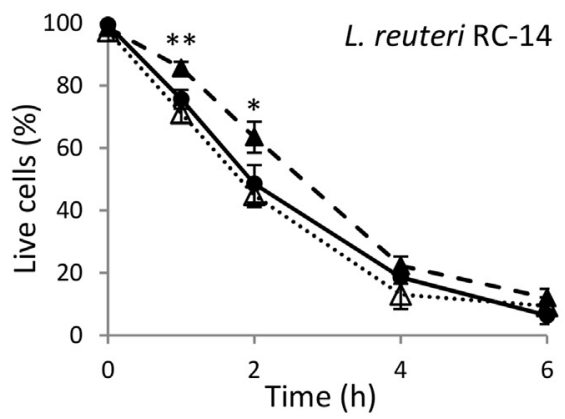

D

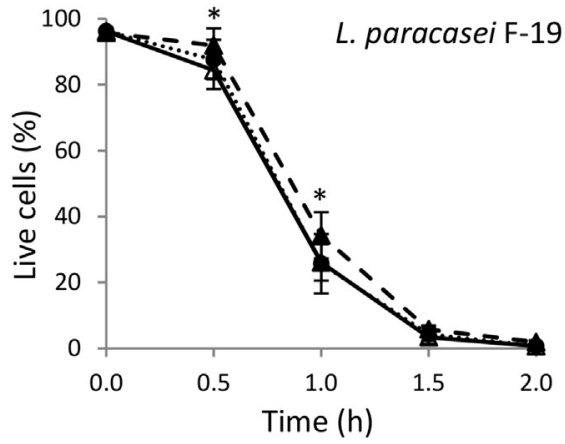

Fig. 1. Survival of probiotic Lactobacillus strains (A) L. fermentum PCC, (B) L. reuteri RC-14, (C) L. rhamnosus LGG and (D) L. paracasei F-19 in simulated gastric solution (GS) with $1 \%(w / v)$ of FiberBind 400 ( $\mathbf{A}$, dashed line) or resistant starch ( $\bullet$, solid line), and controls ( $\Delta$, dots). Live cells fractions (\%) were determined by flow cytometry using SYTO $^{\circledR} 13$ and propidium iodide staining and presented by mean values and SD (bars) from triplicate experiments. Significant differences between FiberBind 400 and controls are denoted by asterisks (Student's $t$-test, two-tailed, ${ }^{*} p<.05 ;{ }^{* *} p<.01$ ).
FiberBind 400 produced more diverse microbial communities $(p<.05)$ between 48 and $72 \mathrm{~h}$ fermentation compared to starches.

\subsection{Beta-diversity of microbiota as affected by substrates and sampling time}

Analysis of bacterial beta-diversity (or group diversity) showed clear separation between the fermentation substrates, i.e., potato fiber, resistant starch and native starch, as illustrated by the PCoA plots (Fig. 3A). The group separation was best explained with the use of weighted UniFrac distance matrix (principal components PC1 56\% and PC2 23\%) which consider mostly changes in abundant lineages,

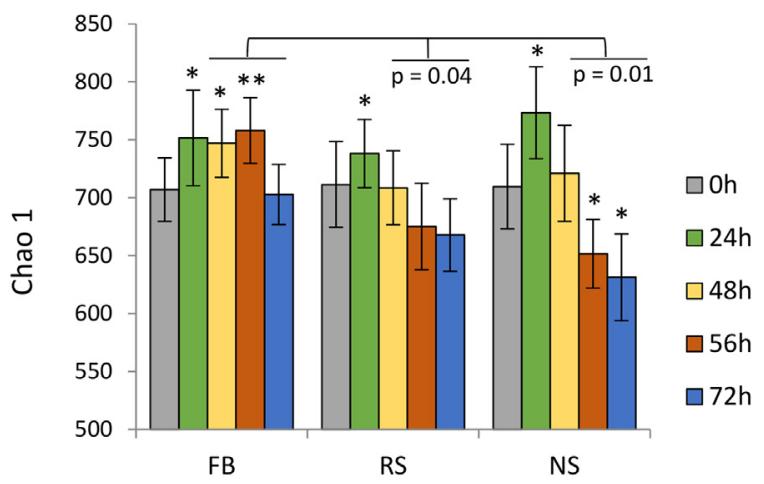

Fig. 2. Alpha-diversity of microbiota during fermentation of FiberBind 400 (FB), resistant starch (RS) and native starch (NS) expressed by Chao1 index. Chao1 values at baseline ( $0 \mathrm{~h}$, grey columns), $24 \mathrm{~h}$ (green columns), $48 \mathrm{~h}$ (yellow columns) and $72 \mathrm{~h}$ (blue columns) fermentation are presented by means and standard deviation (bars) from two independent TIM-2 experiments. Microbiota was analyzed using Illumina NextSeq 500 Sequencing System. Asterisks denote the values significantly different from time $0 \mathrm{~h}$ (two-tailed Student's t-test, $\left.{ }^{*} p<.05,{ }^{* *} p<.01\right)$. Significant differences between FiberBind 400 and starches computed for combined data set (48, 56 and $72 \mathrm{~h}$ fermentation, $n=6$ for each substrate) are shown by $p$-values (non-parametric Student's t-test). (For interpretation of the references to colour in this figure legend, the reader is referred to the web version of this article.) indicating that proportions of dominant rather than rare bacterial taxa contributed to the variance between the groups. The PCoA plots build up across the sampling times (Fig. 3B) showed that the major changes in microbiota occurred after the first $24 \mathrm{~h}$ fermentation $(p=.01)$. Differences between the time-points 48,56 and $72 \mathrm{~h}$ were insignificant $(p=.92)$ suggesting stabilization of microbial community structure.

\subsection{The effect of potato fiber and starches on microbiota composition}

Sequencing analysis of 16S rRNA gene amplicons generated in total 110 OTUs at species-level. Based on results of the beta-diversity analysis, showing similarity in microbiota after $>48 \mathrm{~h}$ fermentation (Fig. 3B), statistical differences were evaluated for the combined data (48, 56 and $72 \mathrm{~h}$ ) obtained for each substrate. Bacterial taxa which relative abundances were significantly affected by FiberBind 400 and the corresponding changes observed in fermentations of starches are presented in Fig. 4. Bacterial populations stimulated highest by FiberBind 400 were assigned to the order Clostridiales, the genera Lachnospira, Butyrivibrio and Mogibacterium, belonging to the phylum Firmicutes, the genera Prevotella and the species Bacteroides ovatus, belonging to the phylum Bacteroidetes, and to the members of the family Desulfovibrionaceae (Desulfovibrio D168) within the phylum Proteobacteria. Bacterial taxa increased to lesser extend by potato fiber, compared to resistant starch and/or native starch, included the genera Clostridium, Bacteroides (B. uniformis), Parabacteroides (P. distasonis), and the families Ruminococcaceae, Christensenellaceae, Clostridiaceae and Mogibacteriaceae. Growth of Bifidobacterium (phylum Actinobacteria) was most extensively promoted by native starch. The family Lachnospiraceae and the species Prevotella copri, prevalent at fermentation start ( $21.3 \%$ and $15.8 \%$, respectively), were decreased by the treatments, highest by native starch. A few bacterial taxa, such as Ruminococcus (proposed taxonomy), R. torques and Paraprevotella, were found in lower abundances in potato fiber fermentations. Changes in other commensals, including increased abundances of Oscillospira, Enterococcus, Bacteroidales, the order RF39 (phylum Tenericutes), and Proteobacteria (Citrobacter and Bilophila), along with a reduction in Roseburia, Ruminococcus, Faecalibacterium prausnitzii and 
A

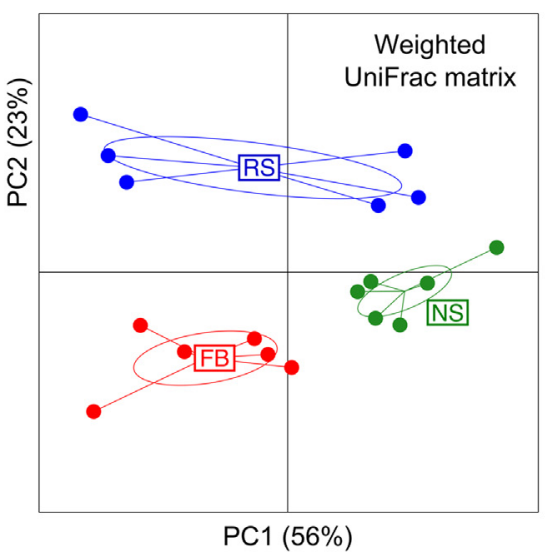

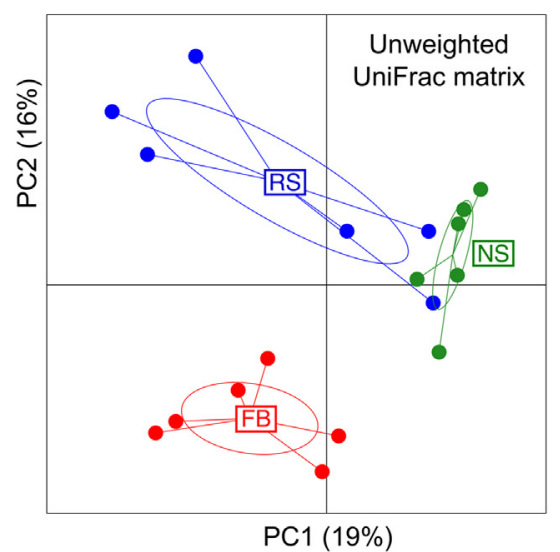

$\mathrm{B}$

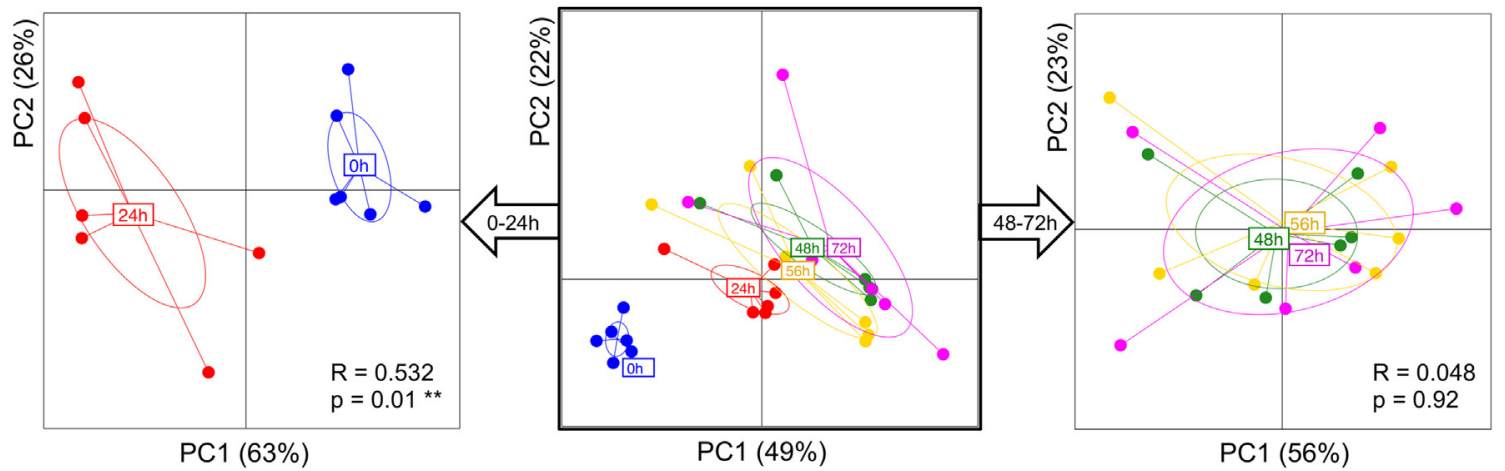

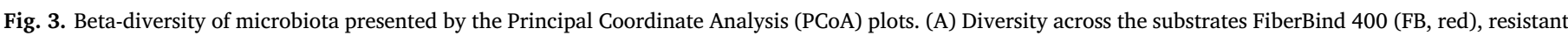

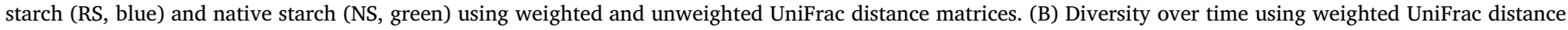

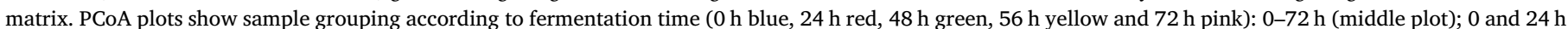

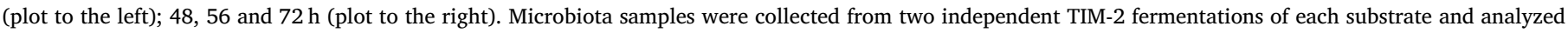

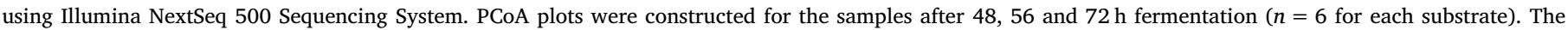

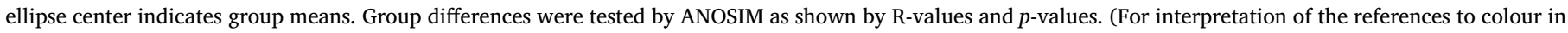
this figure legend, the reader is referred to the web version of this article.)

Erysipelotrichaceae (Eubacterium bioforme), were not significantly different between FiberBind 400 and starches.

\subsection{Production of SCFA and BCFA}

Acetate was the most abundant fatty acid produced in fermentations of FiberBind 400 (61 mmol), followed by propionate $(27 \mathrm{mmol})$ and $\mathrm{n}$ butyrate $(21 \mathrm{mmol})$ (Table 1$)$. The cumulative amounts of total SCFA, total BCFA and isovalerate in fermentations of FiberBind 400 were lower compared to resistant starch $(p<.05)$, while the differences between the substrates in production of other individual fatty acids were statistically insignificant.

\section{Discussion}

\subsection{FiberBind 400 improved survival of Lactobacillus spp.}

We explored the prebiotic potential of potato fiber FiberBind 400, including the ability to improve survival of probiotic Lactobacillus strains exposed to simulated gastric stresses and to modulate the gut microbiota using the TIM-2 colon model. Reference substrates for the experiments were resistant cross-linked potato starch, commonly classified as a prebiotic fiber (X. Yang et al., 2017) and rapidly digestible starch from potato. We observed that bacterial viability in gastric solution was strain-dependent and generally improved by potato fiber, highest in case of $L$. fermentum PCC $^{\circledR}$ and $L$. rhamnosus LGG $^{\circledR}$. Protective effect of potato fiber might be especially advantageous for L. rhamnosus
$\mathrm{LGG}^{\circledast}$, otherwise highly sensitive to simulated gastric conditions. The positive effect of FiberBind 400 on viability of L. reuteri RC- $14^{\oplus}$ and L. paracasei $\mathrm{F}-19^{\circledR}$, though only observed in the first part of incubation $(1-2 h)$, might be essential for bacterial survival, regarding the relatively short transit time in the stomach (Read, Cammack, Edwards, \& Holgate, 1982). Concurrently, the impact of resistant starch and native starch on bacterial viability was insignificant, indicating that nonstarch components of potato fiber, e.g., pectin, might be involved in protection mechanisms. This assumption is based on prior evidence, showing that resistance of Lactobacillus spp. to gastric juice might be improved by treatment with pectins from citrus fruits and sugar beet (Larsen et al., 2018). Moreover, enhancement of bacterial viability by FiberBind 400 was similar or even higher compared to pectins. Bacterial cell surface factors and the nature of molecular interactions, underlying the beneficial effects of potato fiber, need to be clarified.

\subsection{Shifts in microbiota mediated by FiberBind 400 and their association with gut health}

In addition to non-resistant starch, easily degradable by most of the gut commensals, FiberBind 400 is rich in fibers (cell wall polysaccharides and resistant starch) utilized by specific bacterial species. Complex composition of potato fiber resulted in stimulation of various bacterial populations and led to higher diversity of microbiota compared to starches. The major assimilators of fibers belonging to Bacteroides and Prevotella within the phylum Bacteroidetes were generally increased in TIM-2 fermentations. The evidence on health effects 


\begin{tabular}{|c|c|c|c|c|}
\hline \multicolumn{5}{|c|}{ Abundance } \\
\hline p_Firmicutes & Oh, \% & FB & RS & NS \\
\hline f_Lachnospiraceae & 21.3 & 13.1 NS & & 6.93 \\
\hline g_Ruminococcus & 11.2 & 5.44 & 3.76 & 4.81 \\
\hline f_Lachnospiraceae;Other & 8.30 & 6.05 & 5.54 & 5.00 \\
\hline o_Clostridiales & 4.50 & $6.63^{\mathrm{RS}, \mathrm{NS}}$ & & \\
\hline g_Blautia & 2.66 & $1.25^{\mathrm{RS}}$ & 0.88 & 1.22 \\
\hline s_[Ruminococcus] gnavus & 1.59 & $0.67^{\mathrm{NS}}$ & 0.56 & \\
\hline g_[Ruminococcus];Other & 1.14 & $0.81^{\mathrm{RS}, \mathrm{NS}}$ & 1.49 & 1.93 \\
\hline s_Faecalibacterium prausnitzii & 1.09 & 0.09 & 0.08 & 0.08 \\
\hline f_Ruminococcaceae; Other & 0.70 & $3.72^{\mathrm{NS}}$ & 3.09 & 6.54 \\
\hline g_Oscillospira & 0.47 & 3.17 & 1.99 & 3.24 \\
\hline g_Lachnospira & 0.32 & $2.29^{\mathrm{RS}, \mathrm{NS}}$ & 0.07 & 0.07 \\
\hline s_[Ruminococcus] torques & 0.29 & $0.16^{\mathrm{RS}, \mathrm{NS}}$ & & \\
\hline g_Clostridium & 0.12 & $1.92^{\mathrm{RS}, \mathrm{NS}}$ & 7.27 & 8.85 \\
\hline g_Roseburia & 0.10 & 0.02 & 0.02 & 0.01 \\
\hline f_Clostridiaceae & 0.05 & 0.22 NS & 0.65 & 0.80 \\
\hline f_Erysipelotrichaceae & 0.04 & 0.01 & 0.01 & 0.01 \\
\hline g_Butyrivibrio & 0.04 & $0.41^{\mathrm{RS}, \mathrm{NS}}$ & 0.01 & 0.01 \\
\hline$f_{-}[$Mogibacteriaceae] & 0.02 & $0.09^{\text {RS }}$ & & 0.04 \\
\hline s_[Eubacterium] biforme & 0.02 & 0.01 & 0.01 & 0.01 \\
\hline g_Enterococcus & 0.01 & 0.15 & 0.14 & 0.10 \\
\hline f_Enterococcaceae;Other & 0.01 & 0.09 & 0.19 & 0.25 \\
\hline f_Christensenellaceae & 0.01 & $0.08^{\text {NS }}$ & 0.12 & 0.23 \\
\hline g_Mogibacterium & $<0.01$ & $0.65^{\mathrm{RS}, \mathrm{NS}}$ & 0.36 & 0.29 \\
\hline p_Bacteroidetes & & & & \\
\hline s_Prevotella copri & 15.8 & $1.13^{\mathrm{RS}, \mathrm{NS}}$ & 4.18 & 0.12 \\
\hline g_Prevotella & 2.25 & $17.0^{\mathrm{RS}, \mathrm{NS}}$ & 7.19 & 11.1 \\
\hline g_Bacteroides & 1.64 & $4.18^{\mathrm{NS}}$ & 6.48 & \\
\hline s_Bacteroides uniformis & 0.22 & $0.67^{\mathrm{RS}}$ & 3.23 & 0.83 \\
\hline g_Paraprevotella & 0.19 & 0.01 Ns & 0.02 & 0.10 \\
\hline o_Bacteroidales & 0.15 & 2.54 & 3.46 & 3.31 \\
\hline s_Bacteroides ovatus & 0.04 & $0.21^{\mathrm{RS}, \mathrm{NS}}$ & & \\
\hline s_Parabacteroides distasonis & 0.03 & $0.07^{\mathrm{RS}}$ & 0.17 & 0.07 \\
\hline$f_{\text {_[Paraprevotellaceae] }}$ & 0.02 & 0.11 & 0.06 & 0.12 \\
\hline g_Parabacteroides & 0.01 & $0.02^{\mathrm{NS}}$ & & \\
\hline p_Proteobacteria & & & & \\
\hline g_Citrobacter & $<0.01$ & 0.12 & 0.14 & 0.26 \\
\hline f_Enterobacteriaceae & $<0.01$ & $0.12^{\mathrm{NS}}$ & 0.16 & 0.44 \\
\hline s_Desulfovibrio D168 & $<0.01$ & $0.16^{\mathrm{RS}, \mathrm{NS}}$ & 0.02 & \\
\hline f_Desulfovibrionaceae & $<0.01$ & $0.02^{\mathrm{RS}, \mathrm{NS}}$ & & \\
\hline g_Bilophila & $<0.01$ & 0.02 & 0.02 & 0.02 \\
\hline Others & & & & \\
\hline g_Bifidobacterium (p_Actinobacteria) & 0.08 & $0.25^{\mathrm{NS}}$ & 0.51 & 6.21 \\
\hline o_RF39 (p_Tenericutes) & 0.01 & 0.08 & 0.04 & 0.10 \\
\hline
\end{tabular}

Fig. 4. Heatmap showing relative abundances of bacterial taxa in TIM-2 fermentations of FiberBind 400 (FB), resistant starch (RS) and native starch (NS). Microbiota samples were collected from two independent fermentations of each substrate and analyzed by Illumina NextSeq 500 Sequencing System. Bacterial abundances at fermentation start $(0 \mathrm{~h})$ are shown by mean values $(n=6)$. Differences in abundances were evaluated for combined data $(48,56$ and $72 \mathrm{~h} ; n=6$ for each substrate) using the Wilcoxon Rank Sum test and Bonferroni multiplicity correction $(p<.05)$. Abundances of bacterial taxa significantly changed by FiberBind 400 compared to $0 \mathrm{~h}$ are presented by numbers. Significant differences between FiberBind 400 and resistant starch or native starch are denoted by letters RS or NS, respectively. Taxa denoted as "Other" indicate ambiguity in the assignment; taxa in square brackets indicate a proposed taxonomy. The colour key presents the log-transformed mean values of abundances. of Prevotella, stimulated highest by FiberBind 400 is rather inconsistent. Thus, Kovatcheva-Datchary et al. (2015) found that Prevotella contributed to improved glucose metabolism in humans after intake of a fiber-rich diet (Kovatcheva-Datchary et al., 2015), while Pedersen et al. (2016) reported induction of insulin resistance and glucose intolerance in humans and mice by P. copri, the most abundant species of Prevotella (Pedersen et al., 2016). A unique feature of Bacteroidetes genomes is the presence of polysaccharide utilization loci (PULs), encoding the carbohydrate active enzymes (CAZymes) which facilitate the breakdown of complex polysaccharides (Grondin, Tamura, Déjean, Abbott, \& Brumer, 2017). Interestingly, potato fiber was most efficient to support growth of $B$. ovatus, whereas resistant starch was a preferable substrate for B. uniformis. Species-specific utilization of dietary fibers was, most probably, related to the differences in CAZymes activities between the species. Supporting this assumption, preferential utilization of substrates have been reported for Bacteroides species grown in mixed 
Table 1

Cumulative production of short chain fatty acids (SCFA) and branched chain fatty acids (BCFA) after $72 \mathrm{~h}$ fermentation of FiberBind 400, resistant starch and native starch in TIM-2 colon model.

\begin{tabular}{llll}
\hline Fatty acids & $\begin{array}{l}\text { FiberBind 400, } \\
\mathrm{mmol}^{\mathrm{a}}\end{array}$ & $\begin{array}{l}\text { Resistant starch, } \\
\mathrm{mmol}\end{array}$ & Native starch, mmol \\
\hline Acetate & $61.0 \pm 3.6$ & $59.6 \pm 5.6$ & $59.1 \pm 10.8$ \\
Propionate & $26.9 \pm 1.5$ & $31.4 \pm 4.1$ & $23.5 \pm 3.3$ \\
Butyrate & $20.9 \pm 0.6$ & $27.5 \pm 4.1$ & $22.4 \pm 0.5$ \\
Iso-butyrate & $5.3 \pm 0.1$ & $5.1 \pm 0.8$ & $5.6 \pm 0.4$ \\
Iso-valerate & $14.5 \pm 0.4^{*}$ & $19.7 \pm 0.3$ & $16.0 \pm 5.1$ \\
Total SCFA & $108.7 \pm 4.4^{*}$ & $118.4 \pm 3.2$ & $104.9 \pm 14.6$ \\
Total BCFA & $19.8 \pm 0.3^{*}$ & $24.9 \pm 0.5$ & $21.5 \pm 5.5$ \\
\hline
\end{tabular}

a Mean values ( \pm SD) were determined in two independent TIM-2 experiments (lumen and dialysate samples). The amount of fatty acids at the start of fermentations was set to zero. Asterisks shows significant differences between FiberBind 400 and resistant starch (paired Student t-test, ${ }^{*} p<.05$ ). Differences between FiberBind 400 and native starch were insignificant.

cultures (Hamaker \& Tuncil, 2014; Tuncil et al., 2017). Along with the members of the phylum Bacteroidetes, the increased abundances of Clostridiaceae, Ruminococcaceae and Clostridium within the phylum Firmicutes, and the family Enterobacteriaceae within phylum Proteobacteria in TIM-2 experiments can be related to their ability to break down and utilize complex polysaccharides (Abbott \& Boraston, 2008; Thomassen, Vigsnæs, Licht, Mikkelsen, \& Meyer, 2011; Venkataraman et al., 2016). Utilization of the products of potato fiber degradation, or the metabolic cross-feeding interactions (Flint, Scott, Duncan, Louis, \& Forano, 2012), is most probably the main factor favoring growth of Lachnospira, Butyrivibrio, Oscillospira, and Christensenellaceae in potato fiber fermentations. These bacterial populations are commonly associated with a healthier gut environment and found to be predominant in fecal samples from lean individuals over obese (Aguirre \& Venema, 2015; Goodrich et al., 2014; Menni et al., 2017). Concurrently, reduction in butyrate producing bacteria F. prausnitzii, Roseburia, Eubacterium spp., and Blautia, mediated by potato fiber, might be considered unfavorable, regarding their protective role in gut inflammation and metabolic diseases (Cani, 2013; Qin et al., 2012; Upadhyaya, Mccormack, Fardin-kia, \& Juenemann, 2016; Verdam et al., 2013). Another characteristic feature of FiberBind 400 fermentations is an extensive increase in the members of Proteobacteria, specifically Desulfovibrio species. The role of Desulfovibrio in the gut health is still unclear. It was suggested that Desulfovibrio have a positive impact in cancer prevention (Rudi, Ludvigsen, Dirven, \& Steffensen, 2017), whereas other studies highlighted the adverse effects of Desulfovibrio associated with ulcerative colitis (Lennon et al., 2014; Ma, Yu, Zhao, Zhang, \& Zhang, 2018). The genus Bifidobacterium is known to include fiber degrading species, particularly effective in starch utilization (Lockyer \& Nugent, 2017; Thomassen et al., 2011); accordingly, it was highly stimulated by native starch and moderately increased by other substrates in this study. An increase in Bifidobacterium is commonly referred to as beneficial, having the potential to counteract obesity, Crohn's disease and ulcerative colitis (Callaghan \& Van Sinderen, 2016).

Consistent with our results, higher abundances of fecal Oscillospira, Bacteroides, Prevotella, Bifidobacterium, Parabacteroides distasonis, Desulfovibrio and Mogibacterium, as well as lower abundance of P. copri have been reported in human trials after consumption of resistant starches (Alfa et al., 2018; Upadhyaya et al., 2016). Bifidobacterium was also stimulated by potato fiber diets in rats (Paturi et al., 2012; Young et al., 2012). Some other studies, however, reported different results as, e. g., increased numbers of fecal Faecalibacterium and Blautia by potato fiber given to dogs (Panasevich et al., 2015). Discrepancies between the studies can be due to the differences in initial microbiota and composition of potato fibers which can affect efficiency of substrate utilization (Pastuszewska et al., 2009). Based on extensive evidence of structurefunction relationship in microbiota fermentations, we expect that fermentation of FiberBind 400 would mediate unique cross-feeding microbial interactions and specific shifts in microbiota. In the previous TIM-2 experiments with structurally diverse pectins, we found that microbiota composition was associated with degree of methylation of pectins (Larsen et al., 2019). Increased abundances of Lachnospira, Ruminococcus, Prevotella, B. ovatus, and Desulfovibrio spp., as well as reduction of $F$. prausnitzii and $P$. copri in fermentations of FiberBind 400, were observed specifically in fermentations of low-methoxylated (LM) pectins. Supporting these results, pectins from potato fibers have been categorized as LM pectins with methylation degree of $30 \%$ (Yang, Mu, \& Ma, 2018). Similarities between potato fiber and LM pectins indicate that the pectin component seems to be important for microbiota shaping in fermentations of FiberBind 400.

Metabolism of potato fiber and starches by the microbiota was evaluated by measurements of short-chain and branched-chain fatty acids. SCFA have various beneficial functions, playing a key role in the gut immunity, glucose homeostasis, cell proliferation, metabolic processes, etc. (Wang et al., 2019). BCFA, on the other hand, are associated with insulin resistance and cardio-metabolic diseases and commonly regarded as undesirable (Brial, Le Lay, Dumas, \& Gauguier, 2018). Production of total fatty acids by FiberBind 400 was lower compared to resistant starch, indicating slower fermentability of potato fiber. Differences between the substrates in production of individual short-chain and branched-chain fatty acids were mostly insignificant in this study. This finding was unexpected, considering substrate-dependent changes in butyrate and propionate producing bacteria within Lachnospiraceae, Blautia, Bacteroides, Prevotella and Ruminococcus (Louis \& Flint, 2017). Accordingly, similar levels of SCFA and BCFA produced in TIM-2 experiments by different dietary fibers have been reported previously, and it might be attributed to functional redundancy of the microbiota and the metabolic cross-feeding interactions (Aguirre, De Souza, \& Venema, 2016; Larsen et al., 2019).

\section{Conclusions}

This study suggests that potato fiber has a potential to improve survival of probiotic strains of Lactobacillus spp. at gastric conditions, depending on the strain. The protective ability of FiberBind 400 might support efficient delivery of viable probiotics through the stomach when used as, e.g., a component of probiotic containing food. Experiments in the TIM-2 colon model revealed the bifidogenic effect and other shifts in microbiota, suggesting that diet supplementation with FiberBind 400 can selectively stimulate commensals in the gut, among them, health-promoting bacteria. Like many other dietary fibers, potato fiber fermentation led to the production of SCFAs, favorable for colonic health. The overall results indicate that FiberBind 400 has a prebiotic potential and facilitate application of potato fiber as a prebiotic food ingredient with the hypothesized biological and health benefits. Knowledge generated in this study contribute to the growing recognition of the role of fiber products as dietary prebiotics, specifically, in maintaining more balanced microbial communities in the gut. Further extensive human studies, including the impact on microbial dysbiosis associated with a diseased gut, are required to clarify the health benefits of FiberBind 400 .

Supplementary data to this article can be found online at https:// doi.org/10.1016/j.foodres.2019.108644.

\section{Ethical approval}

Studies using fecal donations from healthy volunteers do not require medical ethical committee approval in The Netherlands, since they are considered as non-invasive. Nevertheless, all participants provided informed consent. Results in this manuscript are referred to a pool fecal inoculum and do not directly refer to a particular person. 


\section{Declaration of competing interests}

The authors declare that they have no competing interests.

\section{Funding}

The research was funded by the Danish Council for Strategic Research (DSR, project BioSyn, no. 3050-00005B) and supported by the Brazilian National Council for Scientific and Technological Development (CNPq-Brazil). Carlota Bussolo de Souza received a scholarship 246027/2012-6 from the CNPq-Brazil. This research has additionally been supported by the Dutch Province of Limburg.

\section{References}

Abbott, D. W., \& Boraston, A. B. (2008). Structural biology of pectin degradation by Enterobacteriaceae. Microbiology and Molecular Biology Reviews, 72(2), 301-316. https://doi.org/10.1128/MMBR.00038-07.

Aguirre, M., De Souza, C. B., \& Venema, K. (2016). The gut microbiota from lean and obese subjects contribute differently to the fermentation of arabinogalactan and in ulin. PLoS One, 7(11), e0159236. https://doi.org/10.1371/journal.pone.0159236.

Aguirre, M., \& Venema, K. (2015). Does the gut microbiota contribute to obesity going beyond the gut feeling. Microorganisms, 3, 213-235. https://doi.org/10.3390/ microorganisms3020213.

Alfa, M. J., Strang, D., Tappia, P. S., Graham, M., Van Domselaar, G., Forbes, J. D., ... Lix, L. M. (2018). A randomized trial to determine the impact of a digestion resistant starch composition on the gut microbiome in older and mid-age adults. Clinical Nutrition, 37(3), 797-807. https://doi.org/10.1016/j.clnu.2017.03.025.

Barker, R., Abrahamsson, B., \& Kruusmägi, M. (2014). Application and validation of an advanced gastrointestinal in vitro model for the evaluation of drug product performance in pharmaceutical development. Journal of Pharmaceutical Sciences, 103(11), 3704-3712. https://doi.org/10.1002/jps.24177.

Brial, F., Le Lay, A., Dumas, M. E., \& Gauguier, D. (2018). Implication of gut microbiota metabolites in cardiovascular and metabolic diseases. Cellular and Molecular Life Sciences, 75(21), 3977-3990. https://doi.org/10.1007/s00018-018-2901-1.

Callaghan, A. O., \& Van Sinderen, D. (2016). Bifidobacteria and their role as members of the human gut microbiota. Frontiers in Microbiology, 7, 925. https://doi.org/10.3389/ fmicb.2016.00925.

Cani, P. D. (2013). Gut microbiota and obesity: Lessons from the microbiome. Briefings in Functional Genomics, 12(4), 381-387. https://doi.org/10.1093/bfgp/elt014.

Caporaso, J. G., Kuczynski, J., Stombaugh, J., Bittinger, K., Bushman, F. D., Costello, E. K., ... Knight, R. (2010). QIIME allows analysis of high-throughput community sequencing data. Nature Methods, 7(5), 335-336. https://doi.org/10.1038/nmeth.f. 303.

Chan, S. Y., Choo, W. S., Young, D. J., \& Loh, X. J. (2017). Pectin as a rheology modifier: Origin, structure, commercial production and rheology. Carbohydrate Polymers, 161, 118-139. https://doi.org/10.1016/j.carbpol.2016.12.033.

Etchepare, M. D. A., Raddatz, G. C., Cichoski, A. J., Alexandre José Flores, É. M. M., Barin, J. S., Zepka, L. Q., Jacob-Lopes, E., ... de Menezes, C. R. (2016). Effect of resistant starch (Hi-maize) on the survival of Lactobacillus acidophilus microencapsulated with sodium alginate. Journal of Functional Foods, 21, 321-329. https://doi.org/10.1016/j. jff.2015.12.025.

Flint, H. J., Scott, K. P., Duncan, S. H., Louis, P., \& Forano, E. (2012). Microbial degradation of complex carbohydrates in the gut. Gut Microbes, 3(4), 286-306. https:// doi.org/10.4161/gmic.19897.

Fukunaga, T., Sasaki, M., Araki, Y., Okamoto, T., Yasuoka, T., Tsujikawa, T., ... Bamba, T. (2003). Effects of the soluble fibre pectin on intestinal cell proliferation, fecal shortchain fatty acid production and microbial population. Digestion, 67, 42-49. https:// doi.org/10.1159/000069705.

Gibson, G. R., Hutkins, R., Sanders, M. E., Prescott, S. L., Reimer, R. A., Salminen, S. J., ... Reid, G. (2017). Expert consensus document: The International Scientific Association for Probiotics and Prebiotics (ISAPP) consensus statement on the definition and scope of prebiotics. Nature Reviews. Gastroenterology \& Hepatology. https://doi.org/10. 1038/nrgastro.2017.75.

Gómez, B., Gullón, B., Yáñez, R., Schols, H., \& Alonso, J. L. (2016). Prebiotic potential of pectins and pectic oligosaccharides derived from lemon peel wastes and sugar beet pulp: A comparative evaluation. Journal of Functional Foods, 20, 108-121. https:// doi.org/10.1016/j.jff.2015.10.029.

Goodrich, J. K., Waters, J. L., Poole, A. C., Sutter, J. L., Koren, O., Blekhman, R., ... Ley, R. E. (2014). Human genetics shape the gut microbiome. Cell, 159(4), 789-799. https:// doi.org/10.1016/j.cell.2014.09.053.

Grommers, H. E., \& van der Krogt, D. A. (2009). Potato Starch: Production, modifications and uses. In J. BeMiller, \& R. Whistler (Eds.). Starch (pp. 511-539). San Diego: Elsevier Inc. Academic Press https://doi.org/10.1016/B978-0-12-746275-2.00011-2.

Grondin, J. M., Tamura, K., Déjean, G., Abbott, D. W., \& Brumer, H. (2017). Polysaccharide utilization loci: Fueling microbial communities. Journal of Bacteriology, 199(15) e00860-16.

Hamaker, B. R., \& Tuncil, Y. E. (2014). A perspective on the complexity of dietary fiber structures and their potential effect on the gut microbiota. Journal of Molecular Biology, 426, 3838-3850. https://doi.org/10.1016/j.jmb.2014.07.028.

Johnston, K. L., Thomas, E. L., Bell, J. D., Frost, G. S., \& Robertson, M. D. (2010).
Metabolism resistant starch improves insulin sensitivity in metabolic syndrome. Diabetic Medicine, 27, 391-397. https://doi.org/10.1111/j.1464-5491.2010.02923.x.

Karimi, P., Farhangi, M. A., Sarmadi, B., Gargari, B. P., Zare Javid, A., Pouraghaei, M., \& Dehghan, P. (2016). The therapeutic potential of resistant starch in modulation of insulin resistance, endotoxemia, oxidative stress and antioxidant biomarkers in women with Type 2 Diabetes: A Randomized Controlled Clinical Trial. Annals of Nutrition and Metabolism, 68(2), 85-93. https://doi.org/10.1159/000441683.

Kovatcheva-Datchary, P., Akrami, R., Bjo, I., Kovatcheva-datchary, P., Nilsson, A., Akrami, R., ... Backhed, F. (2015). Dietary fiber-induced improvement in glucose metabolism is associated with increased abundance of Prevotella. Cell Metabolism, 22, 971-982. https://doi.org/10.1016/j.cmet.2015.10.001.

Larsen, N., Bussolo de Souza, C., Krych, L., Barbosa Cahú, T., Wiese, M., Kot, W., .. Jespersen, L. (2019). Potential of pectins to beneficially modulate the gut microbiota depends on their structural properties. Frontiers in Microbiology, 10, 1-13. https://doi. org/10.3389/fmicb.2019.00223.

Larsen, N., Cahú, T. B., Saad, M. S. I., Blennow, A., \& Jespersen, L. (2018). The effect of pectins on survival of probiotic Lactobacillus spp. in gastrointestinal juices is related to their structure and physical properties. Food Microbiology, 74, 11-20. https://doi. org/10.1016/j.fm.2018.02.015.

Lennon, G., Balfe, A., Bambury, N., Lavelle, A., Maguire, A., Docherty, N. G., ... Connell, P. R. O. (2014). Correlations between colonic crypt mucin chemotype, inflammatory grade and Desulfovibrio species in ulcerative colitis. Colorectal Disease, 16(5), 161-169. https://doi.org/10.1111/codi.12503.

Lockyer, S., \& Nugent, A. P. (2017). Health effects of resistant starch. Nutrition Bulletin, 42, 10-41. https://doi.org/10.1111/nbu.12244.

Louis, P., \& Flint, H. J. (2017). Formation of propionate and butyrate by the human colonic microbiota. Environmental Microbiology, 19(1), 29-41. https://doi.org/10. 1111/1462-2920.13589.

Lovegrove, A., Edwards, C. H., De Noni, I., Patel, H., El, S. N., Grassby, T., ... Shewry, P. R. (2017). Role of polysaccharides in food, digestion, and health. Critical Reviews in Food Science and Nutrition, 57(2), 237-253. https://doi.org/10.1080/10408398.2014. 939263.

Ma, H.-Q., Yu, T.-T., Zhao, X.-J., Zhang, Y., \& Zhang, H.-J. (2018). Fecal microbial dysbiosis in Chinese patients with inflammatory bowel disease. World Journal of Gastroenterology, 24(3), 1373-1490.

Mcdonald, D., Price, M. N., Goodrich, J., Nawrocki, E. P., Desantis, T. Z., Probst, A., ... Hugenholtz, P. (2012). An improved Greengenes taxonomy with explicit ranks for ecological and evolutionary analyses of bacteria and archaea. The ISME Journal, 6(3), 610-618. https://doi.org/10.1038/ismej.2011.139.

Menni, C., Jackson, M. A., Pallister, T., Steves, C. J., Spector, T. D., \& Valdes, A. M. (2017). Gut microbiome diversity and high-fibre intake are related to lower longterm weight gain. International Journal of Obesity, 47, 1099-1105. https://doi.org/10 1038/ijo.2017.66.

Panasevich, M. R., Kerr, K. R., Dilger, R. N., Jr., Fahey, G. C., Lynch, G. L., Wils, D., .. Swanson, K. S. (2015). Modulation of the faecal microbiome of healthy adult dogs by inclusion of potato fibre in the diet. British Journal of Nutrition, 113, 125-133. https:// doi.org/10.1017/S0007114514003274.

Pastuszewska, B., Antushevich, H., Tuśnio, A., \& Taciak, M. (2009). Potato dietary fibre Preliminary characterization of the properties and nutritional effects - A review. Polish Journal of Food and Nutrition Sciences, 59(3), 205-210.

Pastuszewska, B., Taciak, M., Tuśnio, A., \& Misztal, T. (2010). Physiological effects of long-term feeding diets supplemented with potato fibre or cellulose to adult rats. Archives of Animal Nutrition, 64(2), 155-169. https://doi.org/10.1080/ 17450390903478885

Paturi, G., Nyanhanda, T., Butts, C. A., Herath, T. D., Monro, J. A., \& Ansell, J. (2012) Effects of potato fiber and potato-resistant starch on biomarkers of colonic health in rats fed diets containing red meat. Journal of Food Science, 77(10), 216-223. https:// doi.org/10.1111/j.1750-3841.2012.02911.x.

Pedersen, H. K., Gudmundsdottir, V., Nielsen, H. B., Hyotylainen, T., Nielsen, T., Jensen, B. A. H., ... Pedersen, O. (2016). Human gut microbes impact host serum metabolome and insulin sensitivity. Nature, 535, 376-381. https://doi.org/10.1038/nature18646.

Qin, J., Li, Y., Cai, Z., Li, S., Zhu, J., Zhang, F., .. Almeida, M. (2012). A metagenomewide association study of gut microbiota in type 2 diabetes. Nature. https://doi.org/ 10.1038/nature11450.

Read, N. W., Cammack, J., Edwards, C., \& Holgate, A. M. (1982). Is the transit time of a meal through the small intestine related to the rate at which it leaves the stomach? Gut, 23, 824-828.

Rudi, K., Ludvigsen, J., Dirven, H., \& Steffensen, I. L. (2017). Genetically and dietary induced obesity associate differently with gut microbiota in a murine intestinal tumorigenesis model. Environmental Disease, 2, 45-54. https://doi.org/10.4103/ed.ed.

Salleh, S. N., Fairus, A. A. H., Zahary, M. N., Bhaskar Raj, N., \& Mhd Jalil, A. M. (2019) Unravelling the effects of soluble dietary fibre supplementation on energy intake and perceived satiety in healthy adults: Evidence from Systematic Review and MetaAnalysis of randomised-controlled trials. Foods, 8(1), 15. https://doi.org/10.3390/ foods8010015.

Starch EU. Starch Europe position on the next CAP (2021-2027). (2018). Retrieved from https://starch.eu/blog/2018/10/26/starch-europe-position-on-the-next-cap-20212027/ Accessed 26 October 2018.

Thomassen, L. V., Vigsnæs, L. K., Licht, T. R., Mikkelsen, J. D., \& Meyer, A. S. (2011). Maximal release of highly bifidogenic soluble dietary fibers from industrial potato pulp by minimal enzymatic treatment. Applied Microbiology and Biotechnology, 90, 873-884. https://doi.org/10.1007/s00253-011-3092-y.

Tuncil, Y. E., Nakatsu, C. H., Kazem, A. E., Arioglu-Tuncil, S., Reuhs, B., Martens, E. C., \& Hamaker, B. R. (2017). Delayed utilization of some fast-fermenting soluble dietary fibers by human gut microbiota when presented in a mixture. Journal of Functional Foods, 32, 347-357. https://doi.org/10.1016/j.jff.2017.03.001. 
Upadhyaya, B., Mccormack, L., Fardin-kia, A. R., \& Juenemann, R. (2016). Impact of dietary resistant starch type 4 on human gut microbiota and immunometabolic functions. Nature Publishing Group, 1-12. https://doi.org/10.1038/srep28797.

Venema, K. (2015). The TNO in vitro model of the colon (TIM-2). In K. Verhoeckx, \& P. Cotter (Eds.). The impact of food bioactives on health: In vitro and ex vivo models (pp. 293-304). Cham (CH): Springer. https://doi.org/10.1007/978-3-319-16104-4.

Venkataraman, A., Sieber, J. R., Schmidt, A. W., Waldron, C., Theis, K. R., \& Schmidt, T. M. (2016). Variable responses of human microbiomes to dietary supplementation with resistant starch. Microbiome, 4, 33. https://doi.org/10.1186/s40168-0160178-x.

Verdam, F. J., Fuentes, S., De Jonge, C., Zoetendal, E. G., Erbil, R., Greve, J. W., ... Rensen, S. S. (2013). Human intestinal microbiota composition is associated with local and systemic inflammation in obesity. Obesity, 21, E607-E615. https://doi.org/ 10.1002/oby.20466.

Wang, M., Wichienchot, S., He, X., Fu, X., Huang, Q., \& Zhang, B. (2019). In vitro colonic fermentation of dietary fibers: Fermentation rate, short-chain fatty acid production and changes in microbiota. Trends in Food Science and Technology, 88, 1-9. https:// doi.org/10.1016/j.tifs.2019.03.005.

Yang, J., Mu, T., \& Ma, M. (2018). Extraction, structure, and emulsifying properties of pectin from potato pulp. Food Chemistry, 244, 197-205. https://doi.org/10.1016/j. foodchem.2017.10.059

Yang, X., Darko, K. O., Huang, Y., He, C., Yang, H., He, S., ... Yin, Y. (2017). Resistant starch regulates gut microbiota: Structure, biochemistry and cell signalling. Cellular Physiology and Biochemistry, 42, 306-318. https://doi.org/10.1159/000477386.

Young, W., Roy, N. C., Lee, J., Lawley, B., Otter, D., Henderson, G., \& Mccann, M. J. (2012). Changes in bowel microbiota induced by feeding weanlings resistant starch stimulate transcriptomic and physiological responses. Applied and Environmental Microbiology, 78(18), 6656-6664. https://doi.org/10.1128/AEM.01536-12.

Zanjani, M. A. K., Ehsani, M. R., Tarzi, B. G., \& Sharifan, A. (2018). Promoting probiotics survival by microencapsualtion with hylon starch and genipin cross-linked coatings in simulated gastro-intestinal condition and heat treatment. Iranian Journal of Pharmaceutical Research, 17(2), 753-766.

Zhang, L., Li, H. T., Shen, L., Fang, Q. C., Qian, L. L., \& Jia, W. P. (2015). Effect of dietary resistant starch on prevention and treatment of obesity-related diseases and its possible mechanisms. Biomedical and Environmental Sciences, 28(4), 291-297. https:// doi.org/10.3967/bes2015.040.

Zhao, X., Andersson, M., \& Andersson, R. (2018). Resistant starch and other dietary fiber components in tubers from a high-amylose potato. Food Chemistry, 251, 58-63. https://doi.org/10.1016/j.foodchem.2018.01.028. 